\title{
Correction to: Sorption separation of Eu and As from single-component systems by Fe-modified biochar: kinetic and equilibrium study
}

\author{
Vladimír Frišták $^{1} \cdot$ Barbora Micháleková-Richveisová $^{6} \cdot$ Eva Víglašová $^{3}$. \\ Libor Ďuriška ${ }^{4} \cdot$ Michal Galamboš $^{3} \cdot$ Eduardo Moreno-Jimenéz $^{5} \cdot$ Martin Pipíška $^{2}$. \\ Gerhard Soja ${ }^{1}$
}

Published online: 26 October 2017

(C) Iranian Chemical Society 2017

\section{Correction to: J IRAN CHEM SOC (2017) \\ 14:521-530}

DOI 10.1007/s13738-016-1000-1

Unfortunately, the address of Barbora Micháleková-Richveisová is wrong in the published article. The correct address is given below as number 6 .

The online version of the original article can be found under doi:10.1007/s13738-016-1000-1.

Vladimír Frišták

fristak.vladimir.jr@gmail.com

1 Energy Department, Environmental Resources and Technologies, Austrian Institute of Technology $\mathrm{GmbH}$, Tulln, Austria

2 Department of Chemistry, Trnava University, 91843 Trnava, Slovak Republic

3 Department of Inorganic Chemistry, Faculty of Natural Sciences, Comenius University in Bratislava, Mlynská Dolina, Bratislava, Slovak Republic

4 Faculty of Materials Science and Technology in Trnava, Slovak University of Technology in Bratislava, Paulínska 16, Trnava, Slovak Republic

5 Departamento de Química Agrícola y Bromatología, Universidad Autónoma de Madrid, Madrid, Spain

6 Department of Ecochemistry and Radioecology, University of SS. Cyril and Methodius, Trnava, Slovak Republic 